\title{
Más allá de los límites del Estado. Instituciones católicas y evangélicas de partidos del Gran Buenos Aires (Argentina) en la implementación de políticas públicas sobre drogas
}

\author{
DANIEL JONES* \\ SANTIAGO CUNIAL**
}

Artículo recibido: 14 de octubre de 2016

Artículo aprobado: 23 de marzo de 2017

Doi: http://dx.doi.org/10.12804/revistas.urosario.edu.co/desafios/a.5225

Para citar este artículo: Jones, D. \& Cunial, S. Más allá de los límites del Estado. Instituciones católicas y evangélicas de partidos del Gran Buenos Aires (Argentina) en la implementación de políticas públicas sobre drogas. Desafíos, 29(2). 85-123. doi: http://dx.doi.org/10.12804/ revistas.urosario.edu.co/desafios/a.5225

\section{Resumen}

El articulo explora las relaciones de las organizaciones de la sociedad civil (OSC) identificadas con un credo religioso que se dedican al tratamiento de los consumos de drogas, con el Estado, otras OSC y otros actores no estatales. El objetivo es describiry analizar

\footnotetext{
* Doctor en Ciencias Sociales (Universidad de Buenos Aires) y licenciado en Ciencia Política (Universidad de Buenos Aires). Investigador adjunto del Consejo Nacional de Investigaciones Científicas y Técnicas (CONICET) e Instituto de Investigaciones Gino Germani (Universidad de Buenos Aires). Correo electrónico: danielprotestantes@gmail. com. ORCID: http://orcid.org/0000-0002-8823-8587

** Magíster en Ciencia Política (Universidad Torcuato Di Tella) y Licenciado en Ciencia Política (Universidad de Buenos Aires). Becario del Consejo Nacional de Investigaciones Científicas y Técnicas (CONICET) e Instituto de Investigaciones Gino Germani (Universidad de Buenos Aires).Correo electrónico: cunialsantiago@gmail.com. ORCID: http:// orcid.org/0000-0002-4657-7388
} 
Los vinculos entre dichas organizaciones, el Estado (en sus distintos niveles, organismos y poderes) y otras organizaciones no estatales (iglesias, federaciones de Organizaciones No Gubernamentales, redes trasnacionales, partidos politicos), en el proceso de implementación de politicas públicas de drogas en partidos del Gran Buenos Aires (PGBA), territorio conocido popularmente como el "conurbano". Analizamos tres dimensiones de los vínculos entre estas OSC religiosas y el Estado: las relaciones económicas; la articulación en los tratamientos propiamente dichos; $y$ los argumentos de sus referentes para explicar la falta de apoyo y / o articulación. Además, describimos el tipo de relaciones de estas instituciones con otras OSC y otros actores no estatales que dan origen, colaboran en el funcionamiento y permiten el sustento económico de estos dispositivos. El artículo se basa en observaciones y entrevistas a referentes instituciones evangélicas y católicas orientadas a la atención de usuarios con consumos de drogas en la Ciudad de Buenos Airesy los partidos del GBA.

Palabras clave: drogas, politicas públicas, iglesias, Argentina

\title{
Beyond the Limits of the State. The Role of Catholic and Evangelical Institutions of Gran Buenos Aires (Argentina) in the Implementation of Public Policy on Drugs
}

\begin{abstract}
The article explores the relations of civil society organizations (CSOs), identified with a religious creed, in terms of their treatment of drug use vis-à-vis the state, other CSOs and other non-state actors. The main objective of the article is to describe and to analyze the links between these organizations, the state (at different levels, agencies and authorities) and other non-governmental organizations (churches, federations of NGOs, transnational networks, political parties) in the process of implementation of drug policies in Gran Buenos Aires - a territory which is popularly known as the "Metropolitan Area" in Argentina. We analyze three dimensions of the links between religious CSOs and the state in Argentina: (i) economic relations; (ii) the joint delivery of treatments; and (iii) the arguments of CSOs to explain the lack of support from the state. In addition, we describe the type of relationships of these institutions with other CSOs and other non-state actors. The article is based on observations and interviews with leaders of Evangelical and Catholic institutions dedicated to drug users in the city of Buenos Aires.
\end{abstract}

Keywords: Drugs, policies, churches, Argentina 


\title{
Para além dos limites o Estado. Instituições católicas e evangélicas de Partidos do Grande Buenos Aires (Argentina) na implementação de políticas públicas sobre drogas
}

\begin{abstract}
Resumo
O artigo explora as relações das organizações da sociedade civil (OSC) identificadas com um credo religioso que se dedicam ao tratamento dos consumos de drogas, com o Estado, outras OSC e outros atores não estatais. O objetivo é descrever e analisar os vinculos entre ditas organizações, o Estado (nos seus distintos niveis, organismos e poderes) e outras organizações não estatais (igrejas, federações de Organizações Não Governamentais, redes transnacionais, partidos políticos), no processo de implementação de políticas públicas de drogas em Partidos do Grande Buenos Aires (GBA), território conhecido popularmente como o "conurbano". Analisaremos três dimensões dos vínculos entre estas OSC religiosas e o Estado: as relaçoes económicas; a articulação nos tratamentos propriamente ditos; e os argumentos dos seus referentes para explicar a falta de apoio el ou articulação. Além disso, descrevemos o tipo de relações destas instituiçoes com outras OSC e outros atores não estatais que dão origem, colaboram no funcionamento e permitem o sustento económico destes dispositivos. O artigo baseia-se em observações e entrevistas a referentes instituiçōes evangélicas e católicas orientadas à atenção de usuários com consumos de drogas na Cidade de Buenos Aires e os Partidos do GBA.
\end{abstract}

Palavras-chave: drogas, politicas públicas, igrejas, Argentina

\section{Introducción}

Este artículo explora las relaciones de las organizaciones de la sociedad civil (OSC) identificadas con un credo religioso que se dedican al tratamiento de los consumos de drogas, con el Estado, otras OSC y otros actores no estatales. El objetivo es describir y analizar los vínculos entre dichas organizaciones, el Estado (en sus distintos niveles, organismos y poderes) y otras organizaciones no estatales (iglesias, federaciones de Organizaciones No Gubernamentales, redes trasnacionales, partidos políticos), en el proceso de implementación de políticas públicas de 
drogas en partidos del Gran Buenos Aires (PGBA), territorio conocido popularmente como el "conurbano". Nos centramos en el origen y el funcionamiento de estos dispositivos de tratamiento, principalmente en las relaciones y redes que construyen y en que se insertan. Analizamos tres dimensiones de los vínculos entre estas OSC religiosas y el Estado: las relaciones económicas; la articulación en los tratamientos propiamente dichos; y los argumentos de sus referentes para explicar la falta de apoyo y/o articulación. Además, describimos el tipo de relaciones de estas instituciones con otras OSC y otros actores no estatales que dan origen, colaboran en el funcionamiento y permiten el sustento económico de estos dispositivos.

En esta interacción entre Estado y OSC, sus protagonistas parecen compartir dos premisas básicas. Una es que el Estado detenta el monopolio de la responsabilidad política ante el problema público de las drogas: es el que en última instancia debe garantizar que exista una respuesta en cuanto a tratamientos para dichos consumos problemáticos de su población. La segunda es que las OSC religiosas son actores social y políticamente legítimos para ofrecer atención sociosanitaria ante el uso de drogas. Esta legitimidad se sustentaría en que anteceden temporalmente a la respuesta estatal al problema, cuentan con una expertise singular para brindar tratamiento (que las diferencia de los programas seculares y/o estatales) y poseen una inserción sostenida en el tiempo entre aquellos grupos considerados principales afectados por esta problemática (sectores populares residentes en barrios marginalizados).

Desde la ciencia política, la noción de políticas públicas alude a la idea del Estado en acción (o inacción) (Parsons, 1995): cómo opera en el tratamiento de situaciones social o políticamente problematizadas. Más allá de esta centralidad del Estado resaltada por la bibliografía especializada, según referentes de varias de estas OSC sus dispositivos de tratamiento no han contado con apoyo estatal en su origen, ni en su funcionamiento. La idea de que el Estado es el actor que habilita la posibilidad de incidir en las políticas públicas y la idea de que estas OSC identificadas con un credo religioso (que implementan iniciativas de políticas públicas) no reciben apoyo estatal, además de 
parcialmente contradictorias entre sí, entran en tensión con algunos hallazgos de nuestro estudio.

Para mostrar dichas tensiones, exploramos el lugar de estas organizaciones en las políticas públicas sobre drogas en Argentina, sus relaciones con el Estado y los vínculos con otras OSC y otros actores no estatales ${ }^{1}$ que les dan origen y sustento. Partimos de entrevistas a referentes de 11 organizaciones católicas y evangélicas de PGBA, que funcionan como comunidades terapéuticas o dispositivos de atención ambulatoria $^{2}$ : las católicas Asociación Revivir, Comunidad Cenácolo, Asociación Civil Programa Por Decir, El Palomar y Fazenda da Esperança; las evangélicas ${ }^{3}$ Asociación Civil Emanuel, Centro Vivir Libre, Centro Cristiano Bernabé, Fundación Reto a la Vida, Adictos a Jesús y Asociación Centro Cristiano de Rehabilitación Programa Andrés.

El análisis de la participación de las OSC religiosas en la implementación de las políticas públicas de drogas es relevante por dos motivos. Primero, a nivel de producción académica, existe un área de vacancia. Los trabajos sobre actores religiosos y políticas públicas en la Argentina reciente se concentran en el campo de la sexualidad. El progresivo reconocimiento de derechos sexuales y reproductivos, particularmente desde 2003 con los gobiernos de Néstor Kirchner

\footnotetext{
1 Elegimos la expresión "no estatal" en lugar de "privado" al entender que la primera abarca más actores que la segunda, asociada por la literatura a grupos económicos (Hall y Soskice, 2001). Actor "no estatal" también incluye a ONGs, movimientos sociales, OSC y otros involucrados en la dinámica analizada.

2 Las comunidades terapéuticas constituyen centros residenciales en los que los internos conviven de forma continua con miembros del equipo técnico. Los tratamientos tienen una duración prefijada, a partir de criterios temporales o del logro de ciertos objetivos por los residentes (Comas Arnau, 2010). Un tratamiento ambulatorio implica la asistencia al centro de atención en ciertos horarios a actividades pautadas (grupos terapéuticos, talleres de formación, terapia individual, etc.); el objetivo es conseguir que la persona en tratamiento sostenga la abstinencia del consumo de drogas, indague las causas que lo llevan al consumo, y desarrolle mecanismos de cuidado para su integridad física, psíquica y, en algunos casos, espiritual.

3 Dentro del amplio espectro evangélico, las organizaciones aquí relevadas se inscriben en el pentecostalismo, "un movimiento religioso nacido en los inicios del siglo XX y enraizado en la tradición de la reforma protestante. [...] Los pentecostales [...] mostraron mayor capacidad de crecimiento y se radicaron, principalmente, en las clases populares” (Semán, 2015, pp. 594 y 602).
} 
y Cristina Fernández, desató intervenciones de la jerarquía eclesial y otros grupos católicos e iglesias y federaciones evangélicas en los debates sobre la despenalización del aborto (Vaggione, 2005; Jones et al., 2013; Brown, 2014; Felitti, 2014), la educación sexual integral (Esquivel, 2013; Jones et al., 2010) y el matrimonio para parejas del mismo sexo (Hiller, 2011; Carbonelli et al., 2011; Jones y Cunial, 2012; Vaggione y Jones, 2015). Menor atención se ha puesto en su accionar en los campos educativo y de ayuda social, pese a la fuerte presencia del catolicismo (Zapata, 2004; Giménez Béliveau, 2008) y la creciente mediación evangélica de ayudas sociales (Carbonelli, 2011). Sobre el tópico drogas, en Argentina algunos trabajos exploran el diseño, implementación y evaluación de las políticas de estupefacientes: Camarotti (2011) aborda las disputas e implicancias de los programas de supresión del uso de drogas y de reducción de daños; Corda (2012) indaga los costos económicos, institucionales y de recursos humanos de la política de drogas; y Corda et al. (2014) evalúan su impacto en cuanto a encarcelamientos de jóvenes de clases populares. Por su parte, Corbelle (2013) analiza los aportes de la sociedad civil en los debates legislativos sobre la normativa de drogas, y Cunial (2014) compara las formas en que decisores políticos y hacedores de política pública enmarcan el problema del uso de drogas en Argentina.

En segundo lugar, investigar este tema es políticamente relevante, ya que las decisiones estatales y las iniciativas de la sociedad civil en políticas de drogas han desatado un intenso debate público sobre los modos de abordar sus consumos problemáticos. El estudio de las interacciones entre el Estado y los actores de la sociedad civil es útil para explicar los conflictos y alianzas, así como para evaluar fortalezas y debilidades de las políticas sobre drogas desarrolladas en Argentina, particularmente en el conurbano bonaerense ${ }^{4}$.

\footnotetext{
4 En Argentina, se conoce como el "conurbano" a los 24 partidos del Gran Buenos Aires, un área que rodea a la Ciudad de Buenos Aires, junto a la que constituye un gran conjunto urbano (véase anexo 1). Es un territorio heterogéneo cuyas representaciones más extendidas lo asocian a la concentración y densidad poblacional, la pobreza y marginalidad social (Soldano y Costa, 2015), el peso electoral y el clientelismo político (Vommaro, 2015), y la inseguridad y delincuencia (incluyendo el tráfico y el consumo de drogas). Según el último censo (INDEC, 2010), la población del conurbano casi se duplicó entre 1970 y 2010, con-
} 


\section{Organizaciones de la sociedad civil y políticas públicas}

Conceptualizamos a las organizaciones identificadas con un credo religioso $^{5}$, que se dedican al tratamiento de consumos de drogas ${ }^{6}$, como organizaciones de la sociedad civil (OSC). Según Waisman (2006, p. 65), en América Latina existe una rica tradición asociativa: desde el restablecimiento de la democracia en varios países en la década de 1980 (como Argentina en 1983), sindicatos, asociaciones profesionales, grupos empresarios, iglesias, espacios comunitarios, clubes deportivos, etc., han sostenido una vida interna vigorosa y una creciente presencia pública. Una tendencia global en los últimos treinta años es el aumento de la visibilidad y la participación institucionalizada de este tipo de organizaciones en espacios de decisión política nacionales e internacionales (Mc Adam et al., 2005; Bryce, 2006; citados en Leiras, 2007), pensado como un resurgimiento de la sociedad civil (Cohen y Arato, 1994).

Consideramos a la sociedad civil como una "esfera de provisión de bienestar" alternativa al Estado, el mercado y la familia (Esping Andersen, 2000). Las OSC no son solo prestadoras de servicios para el bienestar, sino también actores políticos cuya legitimidad no se sostiene en la representación que otorga el voto en elecciones (Gon-

centrando 9,9 millones de habitantes (un cuarto de la población total del país). Posee una población joven, una tasa de analfabetismo de 1,4 \% — tres veces mayor que la ciudad de Buenos Aires-y el 13,6\% de las personas entre 15 y 17 no asistía regularmente al sistema educativo al momento del censo (Bruno, 2015). En su panorama religioso, la principal transformación de los últimos 30 años es "el movimiento clave por el cual los evangélicos crecen a expensas de los católicos” (Semán, 2015, p. 586). Según “encuestas realizadas entre 1998 y 2010, [...] al menos el 10 \% de la población del país se declara evangélica y que su participación en ese porcentaje es más fuerte en los sectores populares y [...] en especial en el Gran Buenos Aires. [...] Actualmente es posible encontrar un $20 \%$ de evangélicos sobre el total de la población de esos segmentos sociales” (Semán, 2015, pp. 587 y 597).

5 En adelante utilizamos indistintamente "organizaciones de la sociedad civil identificadas con un credo religioso" u "organizaciones religiosas" para referirnos a las instituciones objeto de nuestro análisis.

6 Con drogas nos referimos a las sustancias ilegalizadas y a las legales (como alcohol y psicofármacos), cuyo consumo problemático puede demandar un tratamiento. 
zález Bombal y Villar, 2005). Las OSC “desarrollan actividades de advocacy ${ }^{7}$, pero pueden incluir otro tipo de estrategias, incluyendo el lobby, la movilización, la participación en espacios de consulta para el diseño de políticas públicas y la colaboración en la implementación y evaluación de políticas públicas" (Leiras, 2007, p. 23).

Las OSC religiosas dedicadas a las temáticas de drogas presentan varias características antes descritas: a) apuntan a la prevención y el tratamiento de un problema considerado de interés público, el uso de estupefacientes; b) intervienen en la implementación de políticas públicas; y c) su legitimidad se sustenta en una tradición de participación de actores religiosos en políticas sociales en Argentina y en su trabajo con los sectores populares.

También tomamos como eje analítico la noción de redes de políticas públicas: una política pública es el resultado de la interacción entre varios actores, con intereses, metas y estrategias divergentes (Scharpf, 1997), que intentan orientar el proceso político en una dirección. Los actores en la red discuten problemas públicos e idean los instrumentos para su solución. La formación y la implementación de una política son resultado de esta interacción. En un cierto plazo estas interacciones pueden crear lazos parcialmente institucionalizados que reducen los costos de transacción (información, tiempo, etc.) propios de los procesos de decisión e implementación política (Williamson, 1985).

Estas redes de políticas públicas asumen diferentes rasgos según dónde se desarrolle la interacción. Soldano y Costa analizan las políticas sociales en los últimos 30 años en el territorio en que se enclavan las organizaciones aquí relevadas; sus observaciones ayudan a entender qué procesos operaron en la consolidación de las organizaciones religiosas como mediadoras de las políticas públicas:

\footnotetext{
7 La incidencia de diferentes actores sobre las decisiones políticas mediante "actividades confrontativas y cooperativas que implican interactuar con el gobierno y otras instituciones públicas" (Tapia et al., 2011, p. 13).
} 
Los circuitos de los recursos estatales se montaron sobre las redes sociales ya instaladas, [...] redes familiares, comunitarias y políticas. [...] La implementación de programas focalizados introdujo nuevas figuras de mediación de los recursos públicos entre los ciudadanos y el Estado. [...] Este conjunto heterogéneo de actores sociales — que en algunos casos va a superponerse con la tradicional figura del puntero político- ejercerá un amplio poder en su territorio, apareciendo a la vez como la cara del Estado frente a los vecinos y, viceversa, la cara del pueblo frente a las autoridades gubernamentales (Soldano y Costa, 2015, pp. 456-457).

La incidencia de las OSC en las políticas públicas depende de sus recursos y las oportunidades del contexto político. Un recurso de ciertos actores religiosos en Argentina, dentro del heterogéneo espectro de la sociedad civil, es su legitimidad diferencial. Mallimaci y Esquivel (2014, pp. 12-13) apuntan que "la Iglesia católica es un actor legitimado como sujeto político a-partidario por encima y por afuera del resto de los partidos y del Estado", en tanto "prevalece una cultura política que naturaliza la presencia de la institución católica en la sociedad política, auspicia su injerencia en la esfera pública, se promueve su participación en la gestión de políticas públicas”. Estas tendencias exceden a la estructura eclesial, remitiendo a una identidad católica que engloba a las organizaciones aquí indagadas. Las iglesias evangélicas, con particulares peso demográfico y visibilidad en el conurbano, "aceptan y buscan integración a diversas instancias de la vida asociativa [...] el barrio, la política” (Semán, 2015, pp. 598599). Como indica Carbonelli (2015, p. 76), "a partir de la crisis de los años 2001 y 2002, las tareas sociales desarrolladas por las iglesias evangélicas fueron reconocidas por actores políticos como una instancia legítima para resolver problemáticas sociales".

La participación de estos actores puede darse en diferentes etapas: la literatura especializada en políticas públicas distingue entre momentos predecisorios, decisorios y posdecisorios (Theodoulou, 2013). En el primer momento, los problemas políticos son definidos y puestos en la agenda pública. En el segundo, se diseñan y adoptan las políticas para intentar resolver el problema público. En el momento posdecisorio, las 
políticas son efectivamente implementadas, monitoreadas y evaluadas. La complejidad del proceso de elaboración e implementación de una política pública se debe a una gran cantidad de factores: diferentes actores intentan influir en el proceso; no todos los actores tienen fijadas las preferencias sobre la cuestión previo a su debate; los procesos de política pública son el resultado de interacciones complejas de diferentes formas de acción estratégica; las percepciones de los problemas y soluciones cambian a lo largo del tiempo (March y Olsen, 1976; Kingdom, 1984). Las OSC pueden influir en cada uno de estos tres momentos; aquí nos centramos en la implementación.

\section{Metodología}

En 2014 relevamos las instituciones orientadas a la atención de usuarios con consumos de drogas en la Ciudad de Buenos Aires y los partidos del GBA a partir de las bases de datos en las páginas web de la Secretaría de Programación para la Prevención de la Drogadicción y la Lucha contra el Narcotráfico (SEDRONAR), la Federación de Organizaciones No Gubernamentales de la Argentina para la Prevención y el Tratamiento del Abuso de Drogas (FONGA) y el Programa de Cooperación entre América Latina y la Unión Europea en Políticas sobre Drogas (COPOLAD). Así elaboramos un listado de 103 instituciones (nueve de ellas no funcionaban o no proveían atención a usuarios de estupefacientes).

De las 94 instituciones que brindaban tratamiento para el consumo de drogas, 25 (es decir, el $27 \%$ del total de la instituciones relevadas en funcionamiento) se identificaron con una orientación religiosa o manifestaron incorporar componentes espirituales en su propuesta. Optamos por considerar como instituciones con orientación religiosa o espiritual a las que se autodefinieran como tales. Primero, accedimos a sus páginas web o perfiles de Facebook — cuando existían-, buscando elementos que explicitaran dicha orientación ${ }^{8}$. Luego las

\footnotetext{
8 La presentación de la institución como religiosa ("Somos una organización católica/ evangélica/judía que...”), la referencia a la utilización de la metodología de los Doce Pasos
} 
contactamos y la respuesta de sus referentes constituyó el elemento central para clasificar las instituciones entre religiosas/espirituales y no religiosas. Visitamos las 25 instituciones identificadas, en las que registramos observaciones y entrevistamos a un referente de cada institución. Para esta ponencia tomamos 11 evangélicas y católicas ubicadas en partidos del GBA. Las entrevistas fueron codificadas y analizadas siguiendo los lineamientos de la teoría fundamentada (Glaser y Strauss, 1967).

\section{El consumo de drogas como problema público y el rol de las OSC identificadas con un credo religioso}

Pese a que la penalización de la tenencia de ciertas sustancias (que devienen ilegalizadas ${ }^{9}$ ) se remonta en Argentina a 1926 — con la sanción de la Ley N 11.331 - recién a fines de la década de 1960 y comienzos de la de 1970 la drogadicción comienza a constituirse como problema público en el país. En 1967 se crea el Fondo de Ayuda Toxicológica (FAT) y en 1973 el Centro Nacional de Reeducación Social (CENARESO). Desde mediados de la década de 1970 empiezan a funcionar, en iglesias, grupos de autoayuda integrados y conducidos por exadictos, sin participación de profesionales. La creación en 1982 del evangélico "Centro de Rehabilitación Cristiano de Adicciones Programa Andrés" — primera comunidad terapéutica de Argentinailustra el rol pionero que las instituciones religiosas han desempeñado ante la problemática.

Con la sanción de la —aún vigente- Ley No 23.737 en 1989, se produce una demanda considerable de tratamientos por derivación judicial como alternativa a las condenas penales. Esta demanda es absorbida por OSC y financiada por el Estado nacional mediante

— que incorpora la creencia en la existencia de un Poder Superior-, o la alusión a entidades trascendentales (Dios, Jehová, Jesús, vírgenes, santos, etc.) como parte del tratamiento.

9 Empleamos la expresión drogas ilegalizadas porque da cuenta del carácter histórico del proceso por el cual la producción, comercialización y consumo de ciertas sustancias han sido considerados prácticas delictivos. 
becas y, posteriormente, por las obras sociales y prepagas obligadas a cubrir los tratamientos (Touzé, 2006). En 1989 el Presidente Carlos Menem crea la SEDRONAR, unificando los objetivos de reducción de la demanda (prevención, tratamiento y capacitación) y control de la oferta (políticas en narcotráfico, lavado de dinero y registro de precursores químicos).

En la última década, desde el Estado nacional se han comenzado a dar respuestas alternativas a la problemática a través de políticas centradas en la promoción de los derechos humanos y la salud pública: la sanción, en 2010, de la Ley N ${ }^{\circ} 26.657$ de Salud Mental y la Ley No 26.934 de Abordaje Integral de los Consumos Problemáticos, promulgada en 2014; la decisión de circunscribir la actividad de la SEDRONAR a la prevención, capacitación y asistencia de adicciones, quitando de su órbita el combate al narcotráfico y asignándolo al Ministerio de Seguridad (Decreto 48/2014); y el nombramiento del sacerdote católico Juan Carlos Molina al frente de la SEDRONAR (en noviembre de 2013, hasta mayo de 2015), primera vez que un religioso ordenado ocupa un cargo político tan alto (secretario de Estado) desde el regreso de la democracia en 1983.

Estos cambios de enfoque han dado mayor visibilidad al rol de organizaciones y figuras católicas y evangélicas en las políticas de drogas ${ }^{10}$. La asunción de Molina en la SEDRONAR y la división de tareas entre ese organismo y el Ministerio de Seguridad cambiaron el encuadre del problema, focalizándolo como una cuestión de inclusión social (Cunial, 2014): se planteó una relación causal entre la exclusión social y el uso de drogas, por lo que el Estado dirigió sus intervenciones a reinsertar a los usuarios con consumos problemáticos de drogas ilegalizadas. En este contexto, los decisores políticos convocaron públicamente a referentes católicos y evangélicos para que asistan en la implementación de las políticas de drogas, por la cercanía de sus organizaciones con los usuarios y su presencia en los barrios más marginados.

\footnotetext{
10 Dichos cambios también han acarreado tensiones entre el Estado y las OSC religiosas, por ejemplo, por la necesidad de adecuación de sus tratamientos a la Ley de Salud Mental para poder recibir financiamiento estatal.
} 


\section{Relaciones con el Estado}

En esta sección analizamos las relaciones que las organizaciones religiosas dedicadas al tratamiento de usuarios de drogas establecen con el Estado. Tomamos el momento de implementación de las políticas de tratamiento de los consumos de drogas con base en los testimonios de los referentes de estas organizaciones. Destacan su trabajo en la atención a los consumidores y las relaciones, de distinto tipo e intensidad, que mantienen con el Estado en dicha instancia, al tiempo que denuncian la falta de articulación en el diseño de las políticas públicas: "Hubo una nueva ley de Salud Mental que hace poco que apareció y demás, que estamos tratando de que le cambien algunas cosas porque no quedó como correspondía porque no nos consultaron" (EvCT $\left.{ }^{11}\right)$.

Analizamos tres dimensiones de las relaciones entre estas OSC y el Estado: las económicas; la articulación en la implementación de los tratamientos propiamente dichos; y los argumentos de sus referentes para explicar la falta de apoyo y/o articulación.

\section{Relaciones económicas}

La literatura especializada señala que uno de los principales capitales que necesita una OSC para poder influir en el diseño e implementación de políticas públicas es el económico (Leiras, 2007, p. 72), esto es, el conjunto de activos físicos y financieros que permiten sostener regularmente las actividades de la organización (incluyendo sus bienes y recursos o los que recibe de manera estable). Al hablar de sus vínculos económicos con el Estado, nuestros entrevistados resaltan que pueden recibir materiales de infraestructura y terrenos en préstamos para proveer sus servicios: "El municipio de San Isidro a nosotros nos da una gran mano. [...] Los tipos nos dan los campos de deportes, nos prestan cosas" (EvCT).

\footnotetext{
11 Para consignar datos esenciales de cada organización al citar a sus referentes entrevistados, seguimos esta nominación: $\mathrm{Ev}=$ Evangélica, $\mathrm{Ca}=$ Católica; CT: Comunidad Terapéutica, Amb: Ambulatoria.
} 
El beneficio al que acceden más comúnmente son las becas que otorga la SEDRONAR: "el lugar es privado y tiene convenio [...] con el Gobierno de la Ciudad [de Buenos Aires], con Minoridad de Provincia [de Buenos Aires], con SEDRONAR. Entonces, ingresan los chicos por una beca" (CaCT). Si bien estas becas no son beneficios del Estado a las organizaciones, estas devienen en insumos vitales para su funcionamiento al ser dirigidas a personas con problemas de consumo de drogas para costear los tratamientos.

Para recibir estos financiamientos, las organizaciones deben cumplir diferentes exigencias. Una es estar inscritas en el Registro Nacional y Permanente de Efectores Asistenciales de la SEDRONAR. En virtud de ello, según indica la normativa, son regular y periódicamente supervisadas por profesionales del Programa de Auditoría, de modo que cada persona derivada en calidad de subsidiada reciba el tratamiento regulado por las normativas vigentes y se controle el cumplimiento, por parte de las mismas, de las condiciones previstas por la Ley $\mathrm{N}^{\circ} 26.657 \mathrm{de}$ Salud Mental y su Decreto Reglamentario N 603/2013, y las pautas de abordaje integral consignadas en la Ley $\mathrm{N}^{\circ} 26.934$ (SEDRONAR, 2015). Es decir, en tanto que el Estado apoya económicamente los tratamientos provistos por algunas OSC (y no otras), refuerza su rol de garante de las respuestas ante el problema de las drogas y su papel en la delimitación de las reglas, procedimientos y, en última instancia, la orientación de las políticas de tratamiento de consumos problemáticos.

Nuestros entrevistados resaltan las tensiones entre recibir pacientes derivados por el "gobierno"12, la importancia de las becas en el financiamiento de sus organizaciones y la necesidad de mantener un buen vínculo institucional, por un lado, versus las exigencias sobre el tratamiento y el funcionamiento burocrático que el "gobierno" les demanda para otorgarles becas a sus pacientes, por el otro.

\footnotetext{
12 La noción de Estado refiere a una forma particular de ordenamiento político con base en la cual se estructuran las relaciones sociales, mientras que el gobierno es el conjunto de personas que conducen el Estado (Abal Medina, 2010, p. 96). Nuestros entrevistados los utilizan indistintamente; como recuperamos sus propios términos, en ocasiones usamos "gobierno" con un sentido equivalente a "Estado", consignando mediante el entrecomillado que es una expresión nativa.
} 
Con el gobierno de la Provincia [de Buenos Aires] es más o menos como con el gobierno nacional: son un mal necesario que siempre es mejor tenerlos de amigos que tenerlos de enemigos. Te derivan gente, si le cobrás, entre 90 y 180 días [después de iniciado el tratamiento]. Así que a lo mejor vos le tenés que dar de comer a una persona, las becas a lo mejor las cobrás y te exigen demasiada cantidad de cosas, de pequeñeces, cuando en realidad tenés a lo mejor pacientes con graves problemas y grandes complicaciones. Pero bueno, nada, son cuestiones en donde está bueno tenerlos, por momentos funcionan mejor, por momentos funcionan no tan bien (EvCT).

Dichas exigencias son vistas como un intento del Estado por imponerles su modo de abordaje al problema de las drogas. Esta negociación (asimétrica) entre actores puede interpretarse como un mecanismo mediante el cual el Estado disciplina a las OSC en cuanto al modo de atender a los usuarios y delinea los perfiles de quienes pueden y/o deben ser tratados (aquellos por los que el Estado está dispuesto a desembolsar dinero por su tratamiento). En líneas generales, estas organizaciones religiosas trabajan mayoritariamente con poblaciones pobres estructurales con un alto grado de marginalidad, sobre todo jóvenes y varones, que han desarrollado adicciones.

Donahue y Zeckhauser (2008) señalan que en contextos de gobernanza colaborativa ${ }^{13}$ cada actor que forma parte del proceso de implementación de políticas públicas tiene la capacidad de direccionar la intervención en función de sus intereses. Que el Estado pueda distribuir recursos financieros lo habilita a orientar las intervenciones de las organizaciones religiosas y restringir los márgenes de autonomía de las mismas, lo que origina algunas tensiones:

\footnotetext{
13 La noción de gobernanza colaborativa remite a un acuerdo gubernamental mediante el cual uno o más organismos públicos trabajan junto a actores no estatales en procesos de toma de decisiones consensuadas, cuyos objetivos son diseñar o ejecutar una determinada política pública (Ansell y Gash, 2007, p. 544).
} 
[...] Nada de subsidios, pero, ¿por qué? Porque, yo creo, vamos a ser sinceros. SEDRONAR, por ejemplo, ¿no? Ellos te quieren ayudar, te quieren dar un subsidio, ¿no? Pero son personas que ellos quieren implantar lo que ellos realmente quieren. Y muchas veces no es así, porque nosotros tenemos ya nuestro sistema de poder ayudar a los chicos. [...] A veces te quieren imponer psiquiatras acá adentro y como te digo, un psiquiatra no te va a decir, "hermano, lo que vos estás pasando...", ¿̇me entendés? Nosotros lo que necesitamos es, primeramente, ayuda económica (EvCT).

Este testimonio alude a una estructura de profesionales mínima exigida desde la SEDRONAR para otorgar apoyo económico ${ }^{14}$. El incumplimiento de los requisitos que esta exige inhabilita a las instituciones a recibir a personas becadas para su tratamiento u otro tipo de beneficios económicos. La falta de recursos propios de muchas de estas organizaciones limita su capacidad de acción, al mismo tiempo que actualiza el rol tutelar del Estado sobre las OSC en la implementación de políticas públicas:

[...] Hemos pedido ayuda, ¿no? y yo he llamado al SEDRONAR, he hablado con un coordinador, una parte bastante importante,

\footnotetext{
14 Conforme la Resolución SEDRONAR No 885/01 los requisitos exigidos para la inscripción en el Registro Nacional y Permanente de Efectores Asistenciales son: 1) Personería jurídica; 2) Estatuto; 3) Acta de la última asamblea y designación de autoridades; 4) Contrato societario (para sociedades civiles y comerciales); 5) Acta de constitución de sociedad; 6) Habilitación municipal; 7) Planos; 8) Constancia de inscripción ante la AFIP; 9) Título de propiedad o contrato de locación o de comodato; 10) Reglamento interno; 11) Seguros de responsabilidad civil comprensiva y mala praxis de cada uno de los profesionales de la salud que pertenezcan al equipo de la institución; 12) Último balance, de ser reciente la constitución de la personería, acompañar nota aclaratoria con informe de contador público matriculado; 13) Matriculación habilitante de los directivos; 14) Listado de recursos humanos con sus respectivos currículos (actualización periódica); 15) Programas preventivos y o asistenciales; 16) Organigrama de la institución; 17) Las entidades de bien público deben acompañar copia certificada de la inscripción de sus estatutos en el registro de entidades de bien público; 18) Los establecimientos que presten servicios a Obras Sociales, deberán acompañar constancia de inscripción vigente en el Registro de Prestadores de la Superintendencia de Servicios de la Salud. En caso de tratarse de instituciones que prestan asistencia deberán aportar además: 19) Habilitación sanitaria (incluye puntos 1-15); 20) Convenio con centro de emergencia; y 21) Convenio con centro sanitario u hospital más cercano.
} 
inclusive recomendado y, viste, me dijo "mirá, las instituciones como las tuyas no pueden recibir la ayuda necesaria porque no entran dentro de los programas". O sea, vos imaginate que en un centro como el nuestro no podemos internar y tener un chico internado con controles de los médicos, o de un psiquiatra para poderlo medicar, y ellos medican al chico (EvCT).

No obstante, la falta de financiamiento por parte del Estado no siempre es considerada un obstáculo. Si las relaciones económicas con el Estado implican cierto desgaste (por el tiempo y la energía que dedican a cumplir requisitos burocráticos), su ausencia puede pensarse en clave de una mayor autonomía de acción:

[La SEDRONAR] no puede ayudar a XX [su institución] porque es diferente la metodología nuestra [a] la ley de salud mental. [...] El trabajo con el gobierno implica someter, eh, someterse a ellos, ¿no? Acá, nuestra metodología no es política, es más, somos como independientes (CaCT).

\section{Articulación para y en el tratamiento}

Un segundo tipo de relación entre estas organizaciones religiosas y el Estado se da a partir de la derivación de usuarios de drogas judicializados para su tratamiento y la acción complementaria con los sistemas sanitario y educativo.

Las políticas públicas son implementadas en redes relativamente estables, formales e informales, en las que interactúan organismos públicos y organizaciones no estatales que agrupan y movilizan recursos para desarrollar una política (Kenis y Schneider, 1991). Los entrevistados señalan cómo las interacciones regulares de sus OSC con actores del poder judicial y de los sistemas de salud y educativo agilizan los tratamientos de usuarios de drogas. 
Mencionan acuerdos con el poder judicial para que se deriven usuarios judicializados a sus instituciones ${ }^{15}$. La vigente Ley $\mathrm{N}^{0} 23.737$ penaliza la tenencia para el uso personal como medida orientada a disminuir la demanda de drogas ${ }^{16}$. Dicha medida puede suspenderse (e incluso eliminarse) si el usuario depende física o psicológicamente de la sustancia y se somete a un tratamiento de rehabilitación. En función de esta normativa y de la decisión de jueces, varias instituciones relevadas funcionan como una alternativa para que los usuarios con problemas con la ley puedan cumplir su condena en un lugar que no sea la cárcel. De hecho, referentes de estas organizaciones señalan un flujo regular de personas judicializadas como una parte numéricamente significativa de sus pacientes. Estos vínculos fluidos reducen los costos de transacción (tiempo, información, etc.) entre las organizaciones religiosas y el poder judicial, generando beneficios que devienen de la capacidad de los actores de realizar acuerdos creíbles y sostenibles en el tiempo para implementar políticas públicas (Spiller y Tommasi, 2007):

Hay muchos jueces que conocen el método de XX [nombre de su institución] y los mandan, chicos que tienen la causa encautada (SIC), robó un auto, tuvo una pelea en la disco, estaba drogado, la familia de él estaba drogada y el juez sabe que estaba drogado y le recomienda un tratamiento, una medida alternativa, ¿no? En vez de ir a hacer un servicio para alguna cosa, recomienda un tratamiento porque se da cuenta que él es adicto y ahí lo manda para XX (CaCT).

$\mathrm{Al}$ menos dos organizaciones que reciben personas derivadas judicialmente para tratamientos por consumos de drogas, como medida alternativa a la cárcel, no son reconocidas (ni apoyadas económica-

\footnotetext{
15 No encontramos acuerdos formales que sustenten las afirmaciones de los entrevistados; inferimos que estos revisten un carácter informal y se basan en los vínculos de confianza entre miembros del poder judicial y de dichas instituciones.

16 "Será reprimido con prisión de uno a seis años y multa de trescientos a seis mil australes el que tuviere en su poder estupefacientes. La pena será de un mes a dos años de prisión cuando [...] surgiere inequívocamente que la tenencia es para uso personal"' (Ley $\mathrm{N}^{\circ}$ 23.737, Art. 14).
} 
mente) desde la SEDRONAR por no cumplir con requisitos de la normativa vigente. Esta situación refleja cómo las redes de políticas públicas no suponen relaciones unívocas (ni siquiera consistentes) entre las OSC y los distintos poderes y dependencias estatales.

En lo que concierne al sistema de salud, los referentes entrevistados resaltan la acción conjunta de sus organizaciones con hospitales públicos, Centros de Salud y Acción Comunitaria (CeSAC) y Centros de Prevención de las Adicciones (CPA). Dichas relaciones agilizan el acceso a servicios médicos de aquellos usuarios que lo necesiten. En cuanto al sistema educativo, señalan que algunos jóvenes internados en sus comunidades son enviados a concluir la secundaria a escuelas públicas de la zona, así como detallan la prevención que realizan en escuelas públicas mediante charlas sobre el consumo de estupefacientes.

Como adelantamos, las articulaciones entre el Estado y las organizaciones religiosas configuran redes de políticas públicas orientadas a solucionar los problemas de coordinación entre actores interesados en el asunto. Según Börzel (1997, p. 15):

en un entorno dinámico y crecientemente complejo, donde la coordinación tiende a dificultarse si no a imposibilitarse [...], la gobernanza se hace cada vez más factible solo en los policy networks, proveyendo una estructura para la coordinación horizontal eficiente de los intereses y las acciones de los actores corporativos públicos y privados, mutuamente dependientes de sus recursos".

Gobernar, entonces, es siempre un proceso interactivo e iterativo (las relaciones entre actores involucrados se repiten y eventualmente se institucionalizan en el tiempo) porque ningún agente, sea público o privado (no estatal), tiene suficientes conocimientos ni capacidad de emplear recursos para resolver unilateralmente los problemas (Stoker, 1998), tal como describen los entrevistados las respuestas al consumo de drogas mediante un complejo entramado institucional. 


\section{Falta de apoyo y/o articulación}

Así como varias de estas organizaciones religiosas reciben financiamiento y/o coordinan con instancias del Estado para el tratamiento que proveen, algunos referentes subrayan una falta de apoyo (y/o articulación con) del mismo. Las distancias y/o tensiones entre dichas OSC y el Estado ameritan explorarse en tanto inciden en la implementación de políticas públicas sobre drogas, particularmente en la oferta de tratamientos para los usuarios. ¿Qué dinámicas explican esta desconexión? ¿Qué argumentos ofrecen los referentes de las OSC?

Una primera respuesta parte de la percepción negativa de los entrevistados sobre el gobierno y los políticos: recibir ayuda del Estado o de dirigentes políticos podría involucrarlos en prácticas clientelares y corruptas. En referencia a las dinámicas políticas en el conurbano, Auyero (2004, p. 134) sostiene que los punteros y patrones políticos —aquellos que controlan territorios reducidos-, aprovechándose de su posición privilegiada, utilizan recursos estatales con los que: a) resuelven necesidades básicas a los habitantes de los enclaves de pobreza urbana, b) acumulan capital político que les ayuda a conquistar posiciones en el campo político local, y c) mantienen en funcionamiento la maquinaria electoral. Así, tendrían cierto poder de veto sobre quién puede ser beneficiario de los recursos estatales en un determinado territorio. En este sentido, para algunos referentes de OSC este vínculo resulta problemático (por lo que procuran evitarlo), pues los dirigentes políticos y/o funcionarios estatales aprovecharían su trabajo (el de las OSC) en el campo de las drogas para beneficiarse política y electoralmente.

[...] Han venido todos acá, o sea, han venido todos de todos los partidos políticos... no te digo de que acá no se hace política, acá no se hace partidismo, son dos cosas muy distintas. Han venido todos pero siempre en épocas electorales, con propuestas... verdaderamente indecentes, y nunca hemos agarrado viaje [aceptado] (CaCT).

Solamente se les brinda ayuda a las iglesias evangélicas que están bien cargadas de gente. El Estado siempre ayuda a las iglesias que 
pueden votarlos, ¿entendés? Que tienen un caudal de familia, un caudal de gente (EvCT).

En un registro eticomoral, estos referentes denuncian el interés espurio de dirigentes políticos, por un lado, en obtener beneficios económicos de la articulación con los dispositivos terapéuticos y, por el otro, en la capacidad de movilización de las iglesias evangélicas. La ayuda estatal estaría supeditada a que la organización religiosa movilice un número significativo de personas, que le reditúe al dirigente político, bajo el imaginario y/o la experiencia de la cantidad de seguidores y el poder de movilizarlos ${ }^{17}$. Dichas percepciones explicarían por qué algunas de estas organizaciones — tanto católicas como evangélicas- declaran que no quieren o no pueden vincularse con gobiernos o dirigentes políticos. Este distanciamiento es consonante con lo registrado por otras investigaciones sobre el conurbano: "Lejos de pensar estos barrios como espacios de puro dominio de los 'punteros', [...] las relaciones políticas barriales están hechas de regulaciones de los intercambios y de evaluaciones morales que construyen los criterios de justicia en el vínculo entre referentes políticos y vecinos" (Vommaro, 2015, p. 387).

Una segunda respuesta sobre esta desconexión con el Estado la dan algunos entrevistados de organizaciones evangélicas y se centra en la desigualdad simbólica y jurídica ante la Iglesia católica. Si bien la igualdad religiosa ha sido una demanda histórica de los evangélicos en Argentina (Wynarczyk, 2009; Carbonelli y Jones, 2015), "lo nuevo en el siglo XXI es que el pujante movimiento pentecostal reclama no la separación, sino gozar de los mismos privilegios y derechos de ciudadanía religiosa que el catolicismo, [...] recibir los mismos 'favores'

\footnotetext{
17 Si bien en Argentina la mayoría de la población se identifica como católica (76 \%), los evangélicos constituyen la primera minoría religiosa con el $9 \%$ de la población (Mallimaci, 2013). Según una reciente investigación sobre la inserción evangélica en la gestión pública en los partidos del GBA: "El trabajo social realizado por iglesias y comunidades evangélicas en los barrios más pobres del conurbano desde la década del noventa [...] les permitió ingresar a dinámicas políticas de corte local. Para ello contaron con el reconocimiento de sectores importantes de la clase política, quienes los incluyeron como actores participantes de medidas de asistencia social. [...] La referencia al desarrollo de un liderazgo y de un poder de convocatoria 'natural' identifica uno de los capitales más cotizables en la dinámica política territorial: la confianza” (Carbonelli, 2015, pp. 89 y 92).
} 
que la institución católica dominante" (Mallimaci, 2012, p. 175). Toda organización religiosa no católica está obligada a gestionar una personería jurídica como cualquier otra asociación civil (clubes deportivos, barriales, etc.) para poder acceder a convenios con el Estado ${ }^{18}$ :

Siempre funcionó cuestiones sociales de la iglesia hacia la sociedad, pero $[\ldots]$ las iglesias evangélicas no tenemos personería jurídica de por sí, tenemos solo personería religiosa. Eso significa que no podemos hacer convenio con el Estado o con universidad si no tuviéramos persona jurídica. Entonces, nos obligan a crear o una asociación civil o una fundación (EvAmb).

Una última barrera para articular con el Estado (y también con las obras sociales) son los complejos trámites burocráticos para recibir la ayuda. Dichas gestiones, como las requeridas para obtener la personería jurídica, no resultan sencillas para algunas de estas organizaciones por la escasa educación formal y/o la falta de experiencia administrativa de sus referentes. Su percepción es que, al brindar una solución para una demanda hacia y responsabilidad del Estado, este debería facilitarles los trámites.

Es bastante complicado poder llegar al trabajo con la obra social y con SEDRONAR y toda la (sic), lo que se establece, no, desde el gobierno, si bien ellos están tratando de abrir puertas para que los centros trabajen es medio complicado, o sea, parece que quieren abrir puertas pero cuando vas a hacer un trámite a la Municipalidad, eh, no parece, [risas] esa es la realidad, no parece,

\footnotetext{
18 "En Argentina, la Iglesia católica posee privilegios legales frente al resto de las instituciones religiosas. Si bien el catolicismo no es la religión oficial, la Constitución Nacional (Artículo $2^{\circ}$ ) establece que el Estado sostiene el culto católico y, a su vez, como organización religiosa constituye la única persona jurídica de derecho público (Ley 17.711 del Código Civil). Los creyentes de las otras confesiones encuentran amparada su libertad de culto por la Constitución Nacional (artículos $14^{\circ}$ y $20^{\circ}$ ), pero si sus organizaciones desean ser reconocidas estatalmente deben tramitar su inscripción en el Registro Nacional de Cultos (no católicos), creado por la Ley 21.745 de 1978, y en la Inspección General de Justicia (como cualquier otro tipo de organización que requiera personería jurídica)" (Carbonelli y Jones, 2015, p. 134). Dicha personería jurídica es la que les permite interactuar formalmente con agencias estatales, por ejemplo, para recibir fondos.
} 
porque, eh, lo que vos necesitarías sería que te faciliten, no digo que te regalen nada porque uno tiene que hacer las cosas bien, $[\ldots]$ tenés que estar legalmente todo bien trabajadito y bien armadito, pero como así te faciliten, el hecho, bueno si yo soy una salida para tu municipio, una ayuda, yo te brindo este servicio, de alguna manera, eh, tratá de ayudarme a que yo pueda hacer los trámites más rápido $(\mathrm{EvCT})$.

La ausencia de apoyo estatal no impide que estas organizaciones religiosas ofrezcan y lleven adelante sus tratamientos. Tres de las instituciones aquí relevadas, analizadas en profundidad en un trabajo previo (Camarotti et al., 2015), no reciben financiamiento por parte de la SEDRONAR ni de otras agencias estatales, ni funcionan como prestadoras de prepagas y obras sociales. Esto se debe a la forma en que enmarcan la problemática del consumo de drogas y su abordaje terapéutico. Para ser incluidas en el Registro Nacional y Permanente de Efectores Asistenciales deberían adecuar su tratamiento a los lineamientos que exige la SEDRONAR, previamente descritos. De las entrevistas surge que dichos centros no están dispuestos a modificar sus prácticas terapéuticas (duración prolongada de las internaciones ${ }^{19}$, ausencia de profesionales de la salud, obligatoriedad de las actividades religiosas, entre otras), pues iría en contra de cómo conciben el consumo (una problemática de índole espiritual) y sus causas (la falta de sentido de la vida). En contraposición, estas instituciones pertenecen a redes internacionales de tratamiento de drogas que les brindan diferentes formas de apoyo.

\section{Relaciones con OSC y otros actores no estatales}

En esta sección describimos las relaciones con OSC y otros actores no estatales que dan origen, colaboran en el funcionamiento y permiten el sustento económico de estos dispositivos de tratamiento para dar

\footnotetext{
19 Estas tres instituciones proponen internaciones de entre uno y tres años, excediendo el período máximo contemplado por las becas de la SEDRONAR (un año), así como los tiempos promedio de internación de las comunidades terapéuticas religiosas y no religiosas.
} 
cuenta del complejo entramado relacional por fuera del Estado que (también) hace posible el trabajo de estas organizaciones religiosas.

\section{Orígenes}

Varios relatos sobre el surgimiento de instituciones terapéuticas evangélicas enfatizan la iniciativa de figuras individuales apoyadas por sus comunidades religiosas mediante una propiedad para que allí funcione la personería jurídica de la iglesia como asociación civil. Este fenómeno se condice con el rol que la literatura especializada en políticas públicas y sociedad civil le atribuye a las estructuras de liderazgo institucional: los líderes son cruciales para establecer y mantener reglas institucionales, facilitar el diálogo y consolidar vínculos de confianza con actores estatales y no estatales (Ansell y Gash, 2007, p. 554):

Te explico el testimonio del pastor que es el cabeza de todo el Ministerio. [...] Dios le había puesto en su corazón de poder ayudar a los chicos con problemas de adicciones. [...] Él dice que oraba, oraba, y bueno, hasta que se dio la posibilidad... Le habían regalado allá en [el barrio], le habían regalado a la Iglesia la casa. [...] Seguía teniendo en su corazón de poder abrir un lugar así, porque él no quería ver todas esas cosas que estaba viendo, ¿me entendés? Y bueno, de ahí nació y se abrió XX [nombre de la institución] (EvCT).

Otros dispositivos de tratamiento parten de iniciativas en otros países que desarrollan redes trasnacionales que recalan en Argentina. Según la literatura especializada, la importación institucional es una forma regular de difusión y creación de políticas públicas: los actores políticos y sociales tienden a imitar modelos externos que perciben como exitosos (Weyland, 2011). La importación de modelos de abordaje terapéutico de los consumos de drogas y la inserción de la organización en una red trasnacional fueron resaltadas por varios referentes al describir el origen de sus propuestas. Por ejemplo, la Comunidad Cenácolo es una organización católica iniciada por una monja en Italia, que cuenta con 65 casas de atención distribuidas en 18 países de Europa, África y América. En nuestro país inició sus actividades 
en 2005 y tiene una comunidad terapéutica que atiende a unas 50 personas. Fazenda da Esperança es una organización católica que comenzó en la década de 1980 en Brasil, radicándose en la de 2000 en Argentina, donde cuenta con ocho casas de atención en distintas provincias y 150 personas en tratamiento. La fundación evangélica Reto a la Vida, surgida en España a fines de la década de 1980 y actualmente en más de 30 países, inició sus tareas en Argentina en 1989, en la provincia de Misiones. En 1992 se instaló en el GBA con la llegada de un pastor de España y hoy posee casas de atención en seis provincias, con unos 500 pacientes.

Sus relatos del surgimiento de estos dispositivos enfatizan el rol de una figura individual, con ribetes casi míticos (por su iluminación, voluntad y entrega), pocas veces refieren a un proyecto de origen comunitario y nunca aparece el Estado como un actor relevante en su creación y desarrollo inicial. Para entender estas dinámicas, resulta útil tomar cómo la literatura sobre políticas públicas ha conceptualizado el origen de las mismas y su relación con la implementación. Para el modelo top-down las políticas surgen de manera jerárquica y controlada por el Estado, y su implementación se reduce a un mero trámite administrativo. El modelo bottom-up, en cambio, entiende que las políticas públicas nunca son instituciones "completas" y que, en consecuencia, los actores locales (estatales y no estatales) tienen amplios niveles de autonomía para implementarlas (Theodoulou, 2013, p. 293). Los testimonios analizados ilustran los límites de optar por uno u otro enfoque: los modelos de tratamiento a jóvenes con consumos problemáticos de drogas no surgen sólo desde el Estado, pero tampoco exclusivamente desde las comunidades religiosas. En la práctica conviven propuestas con orígenes gubernamentales y no gubernamentales (centradas en figuras individuales o redes transnacionales).

\section{Funcionamiento}

Al explicar su funcionamiento, los referentes de organizaciones evangélicas dedicadas al tratamiento por drogas mencionan múltiples y diversos vínculos dentro del mundo institucional evangélico. Pueden 
articularse dos grupos de una misma iglesia, uno terapéutico y otro de actividades propiamente religiosas (alabanza y oración), como parte de la contención ofrecida a las personas en tratamiento. Otro vínculo consiste en las derivaciones entre organizaciones evangélicas según las necesidades de los pacientes, las modalidades terapéuticas prestadas y las posibilidades económicas de las organizaciones para sustentarse. Si en la sección previa describimos redes formales e informales entre organizaciones religiosas e instancias estatales, aquí observamos cómo algunas redes adquieren un carácter paraestatal: estas OSC comparten información entre sí y cooperan en la derivación de pacientes sin que el Estado las coordine. Estas relaciones pueden entenderse como "patrones de interacción cerrados" (Henriksen, 1996; citado en Bifarello, 2000, p. 9): esas organizaciones trabajan de manera separada del Estado y ocupan una posición marginal para el mismo.

Los referentes de instituciones evangélicas resaltan la pertenencia a redes institucionales (como el "Programa Vida"20) de intercambio de experiencias e informaciones. Las derivaciones entre dichas organizaciones se basan en compartir una red, el conocimiento mutuo de los dispositivos y/o la gratuidad del tratamiento. Sin embargo, participar de estas redes no supone necesariamente un trabajo terapéutico coordinado entre diferentes organizaciones ni una percepción positiva sobre el tratamiento ofrecido por las otras.

Los lugares evangélicos gratuitos que nosotros conocíamos y que teníamos algún tipo de relación son Reto a la Vida y Remar, son los más renombrados dentro del ambiente evangélico, eh... pero la mayoría no tienen atención médica, atención psiquiátrica... en ese momento era un grupo... internación, una granja, muy... muy crudo el trabajo. Que en algunos casos es efectivo y en otros casos para nada... pero bueno, así eso era lo que era

\footnotetext{
20 "Es una Asociación Civil creada en 2003 en conjunto por diferentes iglesias evangélicas nacionales e internacionales, que tienen en la Argentina sus bases de tareas. Su objetivo fundacional es liberar a los que sufren las adicciones, capacitar operadores socioterapeutas, concientizar a toda la población de la importancia de adquirir una cultura preventiva, basada en cada valor expresado en la Biblia” (Página Web Programa Vida, 16/02/2016).
} 
gratuito y nosotros teníamos alguna relación y hacíamos una derivación, pero después no había un tratamiento compartido. Reto y Remar se hacían cargo de la persona y ellos trabajan con bastante... cerrado, digamos. Después nosotros los esperamos para la reinserción, la segunda etapa... cuando volvían. Y en eso sí, volvíamos a facilitar el grupo (EvAmb).

Sus descripciones ilustran las relaciones de estas instituciones con otras de fuerte anclaje territorial (grass-roots) (Bifarello, 2000) que facilitan y potencian sus intervenciones en los espacios en que estas comunidades actúan. Dentro del mundo evangélico también operan articulaciones entre comunidades terapéuticas e iglesias que no son su congregación de origen, por ejemplo, yendo a tocar música a las celebraciones religiosas o "ir a otras iglesias a hacer teatro, hay un grupo de teatro, eh, solemos ir a dar testimonios y así y nos invitan a que vayamos a dar testimonios" (EvCT). Las visitas para realizar prevención y dar a conocer el trabajo terapéutico de la organización permiten que jóvenes que asisten a estas iglesias sepan de la existencia del dispositivo y accedan a él.

Las experiencias de las OSC católicas exploradas van desde un escaso vínculo con la estructura eclesial hasta aquellas que articulan con diócesis, parroquias y escuelas católicas. Por ejemplo, para actividades de prevención del consumo de drogas y promoción de sus tratamientos, algunas comunidades usan instalaciones de iglesias y escuelas céntricas. En ocasiones, sacerdotes enviados por la diócesis cumplen tareas religiosas (como celebrar misa y confesar o confirmar a los pacientes) esenciales para el dispositivo terapéutico, según sus referentes. En otras oportunidades, las personas en tratamiento son invitadas a escuelas y parroquias católicas para dar "testimonio de su propia historia y de cómo el tema espiritual les fue muy favorable" (CaCT).

- ¿Y cómo es el vínculo con la Iglesia católica, dependen de alguna iglesia particular, cómo es la relación?

-No, eh, las misas, tenemos misas todos los días. El sacerdote, tenemos cuatro sacerdotes que acompañan, ellos vienen acá a hacer la misa, celebra [...] la confesión, las misas, por ahí hacemos 
retiro, con los chicos, los sacerdotes, acompañan las cosas así, hay una fiesta patronal y alguna cosa, vínculo así directo no hay. [...] El obispo necesita de una charla en un lugar, o en una parroquia, nos invita, nosotros vamos, damos una charla, hacemos un taller, cualquier cosa, voluntariamente para ellos. [...] En esa forma, pero no tenemos una ligazón directa $(\mathrm{CaCT})$.

En cuanto a las relaciones entre organizaciones católicas y organizaciones evangélicas, son pocas las experiencias de derivaciones entre comunidades de distinta pertenencia religiosa. En cambio, varias sí se vinculan con OSC no religiosas que también se dedican al tratamiento para el consumo de drogas en el marco de FONGA y en congresos de comunidades terapéuticas.

\section{Sustento económico no estatal}

Más allá de recibir o no apoyo económico estatal, un mecanismo habitual de financiamiento de las comunidades terapéuticas es a través de las actividades laborales de las personas internadas, mencionado por varios referentes, sobre todo de organizaciones evangélicas. Se ofrecen servicios (de jardinería, pintura, lavado de autos) y/o productos (de huerta, panadería) realizados por los pacientes, que se venden a sus propias familias (como pago de una cuota e involucramiento en el tratamiento), a las comunidades religiosas vinculadas a la comunidad terapéutica y a la población general (vía el "canasteo" en la calle y los medios de transporte).

- ¿Cómo se sostienen económicamente?

-Del propio, de todas las actividades que nosotros hacemos se hace una canasta de productos, de panadería, huerta, manualidades, todas esas cosas, ¿no? Las familias mensualmente aportan 2.500 pesos, esa es la colaboración, la participación de la familia, ella paga 2.500 y nosotros entregamos una canasta de productos, que esa canasta la pueden utilizar para sí mismo o se puede vender, es una forma pedagógica de la familia involucrarse en la recuperación $(\mathrm{CaCT})$. 
Al sustento económico para el dispositivo se suma la función terapéutica que algunos referentes les atribuyen a estas actividades del paciente e, incluso, destacan el involucramiento familiar en el tratamiento que estas habilitan. Como señalamos en otro artículo del equipo (Camarotti et al., 2015), por un lado, el trabajo es fundamental porque disminuye el tiempo libre y "mantiene la mente ocupada", y es visto como una forma privilegiada de incorporar "valores" (esfuerzo, dedicación, autocontrol, etc.) y de desarrollar una "cultura del trabajo". Por otro lado, las actividades laborales de los residentes resultan esenciales para el sostenimiento de algunas instituciones al permitir el funcionamiento cotidiano de la comunidad y generar una parte considerable de los ingresos económicos mediante la comercialización de productos y la prestación de servicios.

Estas organizaciones también se financian mediante las cuotas pagadas por la familia de la persona en tratamiento o su obra social. Asimismo, solicitan y reciben donaciones de comercios, organizaciones barriales y particulares, desde productos de panadería, ropa y muebles para vender, hasta una camioneta para el funcionamiento de la institución y alimentos para los pacientes. Las iglesias que les dieron origen también pueden afrontar algunos gastos.

También identificamos que las redes de OSC pueden funcionar como mediadoras (por ejemplo, transmitiendo información) para que estas organizaciones religiosas tengan acceso a subsidios estatales, procurando no por ello renunciar a cierta autonomía en el trabajo terapéutico y a la búsqueda de financiamiento. Aquellas que optan por una mayor distancia frente al Estado, la compensan parcialmente con su pertenencia a una red internacional. Es el caso de Comunidad Cenácolo, Reto a la Vida y Fazenda da Esperança, que integran redes con sedes en distintas provincias argentinas y en otros países del mundo que colaboran con un flujo de recursos económicos que - junto a otras fuentes - les permiten ofrecer tratamiento en forma gratuita y, a la vez, prescindir de los aportes estatales (Camarotti et al., 2015). 


\section{Discusión y conclusiones}

En este artículo exploramos cuáles son las relaciones de las organizaciones de la sociedad civil (OSC) católicas y evangélicas dedicadas al tratamiento de los consumos de drogas en Partidos del GBA, con el Estado, OSC y otros actores no estatales, en la implementación de políticas públicas. Abordamos su origen y funcionamiento, centrándonos en las redes que construyen y en las que se insertan. Nuestros hallazgos ponen en tensión tanto la idea de que el Estado es el actor que habilita la posibilidad de incidir en las políticas públicas, presente en la literatura especializada, como el argumento de que estos tratamientos no cuentan con el apoyo estatal, sostenido por referentes de varias OSC.

Estas relaciones entre dichas OSC y el Estado tienden a una interacción instrumental (Bombal y Villar, 2005) centrada en implementar una política pública ${ }^{21}$. Opera una delegación (parcial) del Estado a las OSC de su responsabilidad en llevar adelante los tratamientos para consumos de drogas que no necesariamente implica una cesión premeditada de las competencias para abordar la problemática. Lo que sucede más frecuentemente es que, frente a la inacción estatal en ciertas áreas del problema — por ejemplo, prevención en general y tratamientos de mujeres usuarias-, los entrevistados resaltan las iniciativas de sus instituciones para subsanarla. Al dejarlas actuar, el Estado opta por confiarles la responsabilidad sobre la cuestión. Desde estas OSC religiosas no habría un cuestionamiento al monopolio de la responsabilidad política del Estado frente a la problemática de las drogas, pero sí al monopolio de la expertise sobre los tratamientos. Esto resulta evidente, por ejemplo, en la colisión entre los procedimientos de algunas comunidades terapéuticas religiosas y ciertas reglas sanitarias definidas por el Estado.

\footnotetext{
21 Del conjunto de organizaciones exploradas, la distinción según su identificación religiosa — católica o evangélica - no emerge del análisis como un criterio de diferenciación significativo para caracterizar sus vínculos con el Estado. Es la adopción de las OSC de ciertas pautas de intervención establecidas por el Estado la que las habilita a que reciban beneficios económicos — principalmente, becas de la SEDRONAR para cubrir los tratamientos-.
} 
¿Por qué el Estado delega en las OSC? ¿Por qué en estas organizaciones identificadas con un credo religioso? ¿Qué especificidad les permite atribuirse y que les reconozcan un rol protagónico en esta cuestión? En respuesta a estas preguntas, concluimos el artículo esbozando la siguiente interpretación: las OSC afiliadas a un credo religioso actúan ofreciendo tratamiento frente a la problemática del uso de drogas en la medida en que, en comparación al Estado: a) se les atribuyen ventajas por su anclaje territorial ${ }^{22}$ e información de dicho territorio; b) detentan una doble legitimidad, como OSC y como organizaciones religiosas; y, consecuentemente, c) se consideran más eficientes para proveer estos tratamientos.

Primero, creemos que las OSC son vistas por los decisores políticos como poseedoras de capacidades diferenciales para el abordaje de los consumos de drogas. Las instituciones relevadas son consideradas dueñas de acervos de información mayores a los del Estado con respecto a la población específica a ser atendida por sus dispositivos y con una inserción sostenida en las comunidades afectadas, una gravitación de su acción social en la trama asociativa barrial que Carbonelli (2012) conceptualizó como anclaje territorial. Estos rasgos serían evaluados beneficiosos a la hora de ejecutar sus actividades en este campo.

Segundo, las OSC exploradas poseen una doble legitimidad: un reconocimiento ganado en la ciudadanía y/o en decisores que consideran justificado su derecho a influir en las políticas públicas (Bombal y Villar, 2005, p. 4), como OSC y actores religiosos. Por un lado, trabajar junto a organizaciones barriales en la comunidad y otras OSC espe-

22 "El trabajo social ejercido permanentemente por las iglesias evangélicas configura una red asistencial de la cual participan los fieles, pero también los habitantes del barrio y zonas adyacentes, quienes la han incorporado a su repertorio de estrategias de supervivencia. Hemos denominado anclaje territorial a este proceso (Carbonelli, 2012), aludiendo a la gravitación de la acción social evangélica en la trama asociativa barrial. Implica una manera de habitar un espacio geográfico mediante una dinámica pastoral que se imbrica de manera profunda, 'densa' en las problemáticas cotidianas de sus habitantes. La noción de 'anclaje' remarca que dicha penetración no es ni esporádica ni oportunista, sino que responde a planificaciones y decisiones racionalizadas en el largo plazo" (Carbonelli, 2015, pp. 75-76). 
cíficas sobre drogas les otorgaría una legitimidad por la solidaridad con la población afectada y un accionar económicamente desinteresado. Como sugieren los testimonios de sus referentes, el discurso virtuoso sobre la sociedad civil se asocia con una visión negativa sobre el Estado y lo político: "Se ha identificado al Estado como sinónimo de corrupción cuando no de ineficiencia, insensibilidad e inoperancia. Por el contrario, la moralidad se traslada ahora 'liberada' al campo de una sociedad cuya civilidad, ahora voluntaria, expresa la 'nueva' solidaridad individual, fruto de un compromiso personal y directo, implementado en proyectos concretos, no burocráticos y, sobre todo, no políticos" (Bustelo, 2000, p. 36, citado en Arcidiácono, 2011, p. 6). Por otro lado, las OSC analizadas también poseen una legitimidad por su identificación con un credo religioso. ¿Por qué el Estado delega la implementación de una política pública en organizaciones religiosas? Una clave interpretativa es la noción de laicidad subsidiaria:

En la tradición política argentina, la búsqueda de legitimidades en el campo religioso está registrada como parte del ADN de la praxis política. [...] La forma de organizar la política pública contempla en sus instancias de intermediación a las estructuras religiosas presentes en los barrios. [...] Podríamos hablar de una laicidad subsidiaria para el caso argentino, de un Estado que, en paralelo a la conquista de espacios de autonomía y de mayor reconocimiento de derechos ciudadanos diversos, sigue interpelando a las instituciones religiosas en la proyección de sus políticas públicas. [...] Legitima [...] el soporte estatal a las entidades intermedias de la sociedad civil. Soporte que se ve operacionalizado en la transferencia de recursos económicos, en la participación de estas organizaciones en la ejecución de políticas públicas. [...] No solo los decisores gubernamentales piensan la política pública desde la lógica de la subsidiariedad; las propias organizaciones intermedias interpelan las estructuras estatales desde las mismas coordenadas de sentido y sus estrategias de reproducción institucional dependen en buena medida de esos mecanismos de interacción (Esquivel, 2011, pp. 13-16). 
Si bien el concepto de subsidiariedad remite a la Doctrina Social de la Iglesia Católica, que fomenta el protagonismo de la sociedad civil y solo permite la intervención del Estado cuando la actividad de esta no garantice el Bien Común (Esquivel, 2011, p. 15), dicha lógica parece haberse extendido a las organizaciones evangélicas. En estas organizaciones ha operado una progresiva legitimación "desde abajo", pues su trabajo territorial sostenido en el tiempo les ha provisto del reconocimiento de los habitantes de sus barrios, de otras OSC y del propio Estado, produciéndose en los últimos quince años un salto "de redes de asistencia religiosa paralelas al Estado a redes anexadas a la acción estatal" (Carbonelli, 2015, p. 76).

Finalmente, las capacidades diferenciales y la legitimidad dotarían de mayor eficiencia a estas OSC en sus abordajes de consumos problemáticos de drogas. Como observa Arcidiácono (2011, p. 7), "se asume que existe una relación costo-beneficio óptima en la provisión de servicios sociales a cargo de estas organizaciones, ya que al estar cerca de los receptores y de su contexto, conocerían mejor las necesidades del lugar y de la población, controlarían mejor las filtraciones y harían más eficiente la política”. El Estado opta por delegar (parcialmente) las competencias en la materia, dado que estas OSC poseen recursos institucionales y simbólicos que les permiten intervenir mejor en el problema en comparación con las instituciones seculares ${ }^{23}$.

En suma, al implementarse políticas públicas de tratamiento al consumo de drogas en Argentina, el Estado no es el único actor relevante. Asimismo, las OSC identificadas con un credo tampoco cuentan, en su mayoría, con la capacidad y la voluntad de prescindir del apoyo estatal al ofrecer sus propuestas terapéuticas. En ese complejo entramado institucional analizado se desarrollan las políticas públicas que hoy responden a las demandas de tratamiento para los consumos de drogas. Dicho panorama nos lleva a interrogarnos sobre cuán claros

\footnotetext{
23. Adicionalmente, "al estar dispuestas a cooperar con trabajo voluntario, se generaría un mecanismo para 'ahorrar' en recursos humanos que desarrollen las políticas, generando un costo más bajo que el de la provisión de los servicios por parte del Estado” (Arcidiácono, 2011, p. 7).
} 
son los límites entre el Estado y OSC religiosas en este escenario político, considerando la laicidad subsidiaria del Estado argentino que sigue interpelando a las instituciones religiosas en el desarrollo de políticas públicas. Como contrapunto, cabe preguntarse en qué medida la aceptación de las reglas impuestas por el Estado para llevar adelante los tratamientos compromete una lógica más autónoma por parte de sociedad civil organizada.

\section{Referencias}

Abal Medina, J. M. (2010). Manual de ciencia política. Buenos Aires: Eudeba. Ansell, Ch. \& Gash, A. (2007). Collaborative Governance in Theory and Practice. J Public Adm Res Theory, 18 (4), 543-571.

Arcidiácono, P. (2011). El protagonismo de la sociedad civil en las políticas públicas: entre el "deber ser" de la participación y la necesidad política. Revista del CLAD Reforma y Democracia. Recuperado el 4 de agosto de 2016 de http:/ / www.redalyc.org/articulo.oa?id=357533683006

Auyero, J. (2004). Clientelismo politico. Las caras ocultas. Buenos Aires: Capital intelectual.

Bifarello, M. (2000). Public-third Sector Partnerships. A Major Innovation in Argentinian Social Policy. Cuarta Conferencia Internacional ISTR, Dublín, Irlanda.

Börzel T. A. (1997). What's So Special About Policy Networks? An Exploration of the Concept and its Usefulness in Studying European Governance. European Integration Online. Recuperado el 4 de agosto de 2016 de http://eiop.or.at/eiop/texte/1997-016.htm

Brown, J. (2014). Mujeres y ciudadanía. Debates teóricos y politicos sobre derechos (no) reproductivos y sexuales. Buenos Aires: Editorial Teseo.

Bruno, M. (2015). La población del conurbano en cifras. En Kessler, G. (Dir.), El Gran Buenos Aires (pp. 159-191). Buenos Aires: EDHASA.

Carbonelli, M. (2011). Evangélicos y partidos politicos en Argentina. Anclaje territorialy redención de la política. Saarbrücken: Editorial Académica Española. Carbonelli, M. (2012). En el evangelio y en el partido: trayectorias políticas de pastores en el Gran Buenos Aires. Revista Colombiana de Antropología, 48(2), 89-113. 
Carbonelli, M. (2015). Valores para mi país. Evangélicos en la esfera política argentina 2008-2011. DADOS-Revista de Ciências Sociais, 58(4), 981-1015.

Carbonelli, M. \& Jones, D. (2015). Igualdad religiosa y reconocimiento estatal: instituciones y líderes evangélicos en los debates sobre la regulación de las actividades religiosas en Argentina (2002-2010). Revista Mexicana de Ciencias Politicas y Sociales, 225, 133-160.

Carbonelli, M., Mosqueira, M. \& Felitti, K. (2011). Religión, sexualidad y política en la Argentina: intervenciones católicas y evangélicas en torno al aborto y el matrimonio igualitario. Revista del Centro de Investigación, 9(36), 25-43.

Camarotti, A. C. (2011). Política sobre drogas en Argentina. Disputas e implicancias de los programas de supresión del uso y de reducción de daños. Madrid: Editorial Académica Española.

Camarotti, A. C., et al. (2015). Respuestas religiosas y espirituales a los consumos de drogas en el Área Metropolitana de Buenos Aires: perspectivas y prácticas de actores institucionales. $2^{\circ}$ Jornadas de Sociología, Universidad Nacional de Cuyo, Mendoza, Argentina.

Cohen, J. L. \& Arato, A. (1994). Sociedad civily teoría política. México: FCE.

Comas Arnau, D. (2010). La metodología de la Comunidad Terapéutica. Madrid: Fundación Atenea.

Corbelle, F. (2013). Drogas: la audiencia pública. Intervención política y trabajo de campo. Avá. Revista de Antropología, 22, 97-119.

Corda, A. (2012). Sistemas desproporcionados: desproporción y costos económicos, institucionales y humanos de la politica sobre estupefacientes en Argentina. Buenos Aires: Intercambios Asociación Civil-Universidad de Buenos Aires.

Corda, A., Galante A. \& Rossi, D. (2014). Drug Users in Argentina: A "Prohibitionist-Abstentionist" Framework. En Youngers, C. y Pérez Correa, C. (Eds.) In search of Rights: Drug Users and State Responses in Latin America (pp. 33-45). México: CIDE-CEDD.

Cunial, S. (2014). El uso de drogas ilegales como asunto de politica pública en Argentina. (Tesis de maestría no publicada). Buenos Aires: Universidad Torcuato di Tella.

Donahue, J. D. \& Zeckhauser, R. (2008). Public-Private Collaboration. En Moran, M., Rein, M. y Goodin, R. (Eds.), Oxford Handbook of Public Policy (pp. 496-525). Oxford: Oxford University Press.

Esping Andersen, G. (2000). Fundamentos sociales de las economias postindustriales. Barcelona: Ariel. 
Esquivel, J. C. (2011). Repensando un concepto: la laicidad entre la política, la religión y la ciudadanía. Jornadas sobre Alternativas Religiosas en América Latina, Punta del Este, Uruguay.

Esquivel, J. C. (2013). Narrativas religiosas y políticas en la disputa por la educación sexual en Argentina. Cultura y Religión, 7, 140-163.

Felitti, F. (2014). L'avortement en Argentine. Politique, religion et droits humains. Autrepart (La Tour d'Aigues), 73-90.

Giménez Béliveau, V. (2008). Espacios públicos y espacios políticos redefinidos. Reflexiones sobre el accionar de los grupos religiosos en la escena pública en Argentina. Religión y Espacio Público, 49-60.

Glaser, B. \& Strauss, A. (1967). The Discovery of Grounded Theory: Strategies for Qualitative Research. Londres: Weidenfeld and Nicholson.

González Bombal, I. \& Villar, R. (2005). Organizaciones de la sociedad civil e incidencia en políticas públicas. Buenos Aires: Universidad de San Andrés.

Hall, P. \& Soskice, D. (Eds.). (2001). Varieties of Capitalism: The Institutional Foundations of Comparative Advantage. New York: Oxford University Press.

Hiller, R. (2011). Conyugalidad y ciudadanía: disputas en torno a la regulación estatal de lasparejas gay lésbicas en la Argentina contemporánea. (Tesis de doctorado no publicada). Buenos Aires: Universidad de Buenos Aires.

INDEC. (2003). ¿Qué es el Gran Buenos Aires?

INDEC. (2010). Censo Nacional de Población, Hogares y Viviendas 2010.

Jones, D., Azparren, A. L. \& Polischuk, L. (2010). Evangélicos, sexualidad y política: las instituciones evangélicas en los debates públicos sobre Unión Civil y Educación Sexual en la Ciudad Autónoma de Buenos Aires (2003-2004). En Vaggione, J. M. (Comp.). El activismo religioso conservador en Latinoamérica (pp. 193-248). Córdoba: Ferreyra Editor, pp. 193-248.

Jones, D. \& Cunial, S. (2012). Evangélicos contra el "matrimonio homosexual" en Argentina: el activismo político de la federación Alianza Cristiana de Iglesias Evangélicas de la República Argentina (ACIERA). En Peñas Defago, A. y Vaggione, J. M. (Comps.). Actores y discursos conservadores en los debates sobre sexualidad y reproducción en Argentina. Córdoba: Ferreyra Editor, pp. 199-230.

Jones, D., Azparren, A. L. \& Cunial, S. (2013). Derechos reproductivos y actores religiosos: los evangélicos frente al debate sobre la despenalización del aborto en la Argentina contemporánea (1994-2011). Espacio Abierto, 22(1), 110-133. 
Kenis, P. \& Schneider, V. (1991). Policy Networks and Policy Analysis: Scrutinizing a New Analytical Toolbox. En Marin, B. y Mayntz, R. (Eds.). Policy Networks. Empirical Evidence and Theoretical Considerations. Boulder, Colorado: Campus Verlag/Westview Press, pp. 25-62.

Kingdom, J. (1984). Agendas, Alternatives and Public Policies. Boston: Little Brown.

Leiras, M. (2007). La incidencia de las organizaciones de la sociedad civil en las políticas públicas: definiciones, explicaciones y evaluaciones de la literatura especializada local e internacional. En Acuña, C. H. y Vacchieri, A. (Comps.). La incidencia de la sociedad civil sobre las politicas públicas en la Argentina. Buenos Aires: Siglo XXI Editores.

Mallimaci, F. (2012). Política y catolicismo en el gobierno del Dr. Kirchner: recomposición y disputa del poder simbólico. En Parker, C. (Ed.). Religión, cultura y politica en América Latina: nuevos enfoques (a modo de introducción) (pp. 169-198). Santiago: Universidad de Santiago de Chile.

Mallimaci, F. (2013). Atlas de las creencias religiosas en Argentina. Buenos Aires: Biblos.

Mallimaci, F. \& Esquivel, J. C. (2014). La contribución de la política y el Estado en la construcción del poder religioso. Revista Argentina de Ciencia Política 17, 71-89.

March, J. G. \& Olsen, J. (Eds.). 1976. Ambiguity and Choice in Organizations. Bergen: Universitetsforlaget.

Página Web Programa Vida: http://programavida.com.ar/ Visitada el 16 de febrero de 2016.

Parsons, W. (1995). Public Policy: An Introduction to the Theory and Practice of Policy. Aldershot: Edward Elgar.

Scharpf, F. (1997). Games Real Actors Play: Actor Centered Institutionalism in Policy Research. Boulder: Westview.

Semán, P. (2015). La vida religiosa de los sectores populares del Gran Buenos Aires. En Kessler, G. (Dir.). El Gran Buenos Aires (pp. 579-604). Buenos Aires: EDHASA.

Soldano, D. \& Costa, M. (2015). El conurbano bonaerense como territorio asistido. Pobreza, crisis y planes sociales. En Kessler, G. (Dir.). El Gran Buenos Aires (pp. 433-463). Buenos Aires: EDHASA.

Spiller, P. \& Tommasi, M. (2007). The Institutional Foundations of Public Policy in Argentina. Cambridge: Cambridge University Press. 
Stoker, G. (1998). Governance as Theory: Five Propositions. International Journal of Social Sciences, 50 (1), 17-28.

Tapia, A., Bajpai, K., Jansen, J., Yen, J. \& Giles, L. (2011). Seeking the Trustworthy Tweet: Can Microblogged Data Fit the 27 Informational Needs of Disaster Response and Humanitarian Relief Organizations. Octava Conferencia Internacional ISCRAM, Lisboa, Portugal.

Theodoulou, S. (2013). The Structure and Context of Policy Making. En Theodoulou, S. y Cahn, M. (Eds.). Public Policy. The Essential Readings. Nueva York: Pearson.

Vaggione, J. (2005). Los roles políticos de la religión. Género y sexualidad más allá del secularismo. En Vasall, M. (Comp.). En nombre de la vida (pp. 137-169). Córdoba: Católicas por el Derecho a Decidir.

Vaggione, J. \& Jones, D. (2015). La política sexual y las creencias religiosas: el debate por el matrimonio para las parejas del mismo sexo (Argentina, 2010). Revista de Estudios Sociales, 51, 105-117.

Vommaro, G. (2015). El mundo político del conurbano en la democracia reciente. En Kessler, G. (Dir.). El Gran Buenos Aires (pp. 365-399). Buenos Aires: EDHASA.

Waisman, C. (2006). Autonomía, autorregulación y democracia: sociedad civil y Estado bifurcado en América Latina. Postdata 11, 57-74.

Weyland, K. (2011). Cambio institucional en América Latina: modelos externos y consecuencias no previstas. América Latina Hoy, 57, 117-143.

Williamson, O. (1985). The Economic Institutions of Capitalism: Firms, Markets, Relational Contracting. Nueva York: Free Press.

Wynarczyk, H. (2009). Ciudadanos de dos mundos. El movimiento evangélico en la vida pública argentina 1980-2001. Buenos Aires: UNSAM Edita.

Zapata, L. (2004). Una antropología de la gratuidad: prácticas caritativas y políticas de asistencia social en la Argentina. Campos, 5 (2), 107-125. 
MÁs allá de los límites del Estado. Instituciones católicas y eVANGÉlicas de partidos del Gran Buenos Aires (Argentina) / 123 Anexo 1: Mapa de Gran Buenos Aires: Ciudad de Buenos Aires
y 24 partidos del conurbano bonaerense

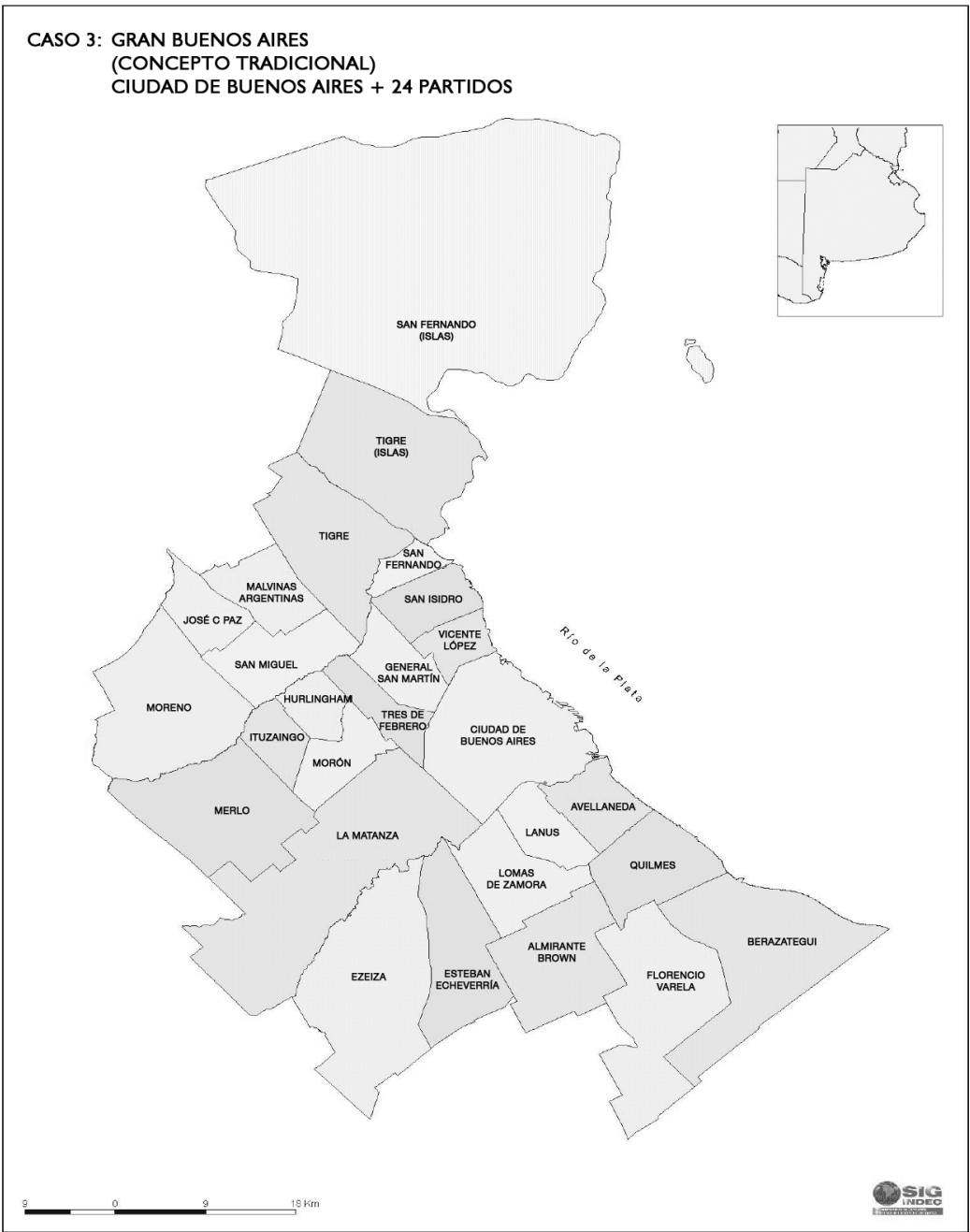

Fuente: INDEC (2003). 